\title{
Free vibrations of axially functionally graded horseshoe arch
}

\author{
Gweon Sik Kim ${ }^{a}$, Sang Jin Oh${ }^{b}$, Tae Eun Lee ${ }^{c}$ and Byoung Koo Lee ${ }^{\text {a }}$
}

${ }^{a}$ Department of Civil and Environmental Engineering, Wonkwang University, 460 Iksan-daero, Iksan-si, Jeollabuk-do 54538, South Korea

${ }^{b}$ Department of Civil and Environmental Engineering, Jeonnam State University, 152 Jookrokwon-ro, Damyang-eup, Jeollanam-do, 57337, South Korea ${ }^{c}$ School of Architecture, Civil and Landscape Engineering, Donggang University, 50 Dongmoon-daero, Buk-gu, Kwangju-si, 61200, South Korea

\begin{tabular}{l}
\hline A R T I C L E I N F O \\
\hline Article history: \\
Received 10 January 2021 \\
Accepted 4 March 2021 \\
Available online \\
4 March 2021 \\
\hline Keywords: \\
Free vibration \\
Functionally graded material \\
Horseshoe arch \\
Natural frequency \\
Mode shape.
\end{tabular}

A B S T R A C T
This paper deals with free vibrations of the axially functionally graded (AFG) horseshoe arch. The
modulus of elasticity and the mass density of AFG material of arch are chosen as a univariate quadratic
function. The differential equations with the boundary conditions that govern the free vibration of such
arch are derived and numerically solved to calculate natural frequencies and mode shapes. Natural
frequencies of this study agree well with those of the finite element ADINA. Parametric studies of the
geometrical and mechanical properties of the arch on frequencies and mode shapes are performed and
extensively discussed.

(C) 2021 Growing Science Ltd. All rights reserved.

\section{Introduction}

Arches are frequently used in many engineering fields because of their beautiful appearance and excellent structural function. The horseshoe arch is an arch shape in which the length of the longitudinal secant line increases from the peak of the arch, reaches its maximum value on the horizontal axis and decreases to the span length of the lower opening. In particular, the horseshoe arch is widely used as a framed structure in the fields of civil, architecture, aerospace, and ship building engineering because it can utilize a wide range of working space under the arch member. Photo 1 shows an example of a horseshoe arch erected as an entrance portal that goes well with a modern building.

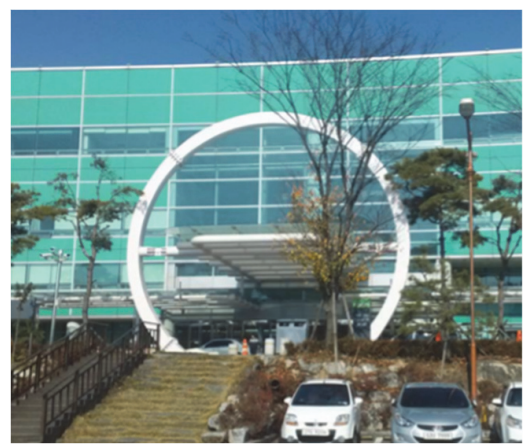

Photo 1. Example of a horseshoe arch erected as a portal at the entrance to Wonkwang University Hospital, Iksan City, Jeollabuk-do (Photo by B.K. Lee)

* Corresponding author

E-mail addresses: bkleest@wku.ac.kr (B.K. Lee) 
Exciting the dynamic load acting on the structure creates an element that weakens the structure function due to the resonance phenomenon of the free vibration characteristics. Therefore, free vibration is one of the important research tasks of structural analysis, from the design stage of the structure to the monitoring soundness of the structure in public use (Rao, 2007). Functionally graded materials have been developed as barriers to protect the thermal environment but have recently been used as a framed structure in many engineering practices due to advances in material technology. Furthermore, axially functionally graded (AFG) materials have excellent structural functionality as a compressive and bending member, as various properties of axial strength and bending stiffness are possible due to the physical properties synthesized from hybrid materials (Horibe \& Mori, 2019).

So far, many studies on the behavior of arch and AFG structures have been published. Considering the research trends of the free vibration of the arch and the structural behavior of AFG structure, it is as follows. Arch's free vibration solutions can be divided into the exact and approximate form solutions. The exact form solution (Tufekci \& Ozdemir, 2006; Lü \& Lü, 2009) has a very complicated solution, so the research results are very rare. The approximate form solution is obtained from the numerical method that calculates mode shapes by numerically integrating the governing differential equation, and eigenvalues of natural frequencies by the determinant search method, and most of research works included here (Joo et al.,1985; Lee et al., 2014, 2016; Nieh et al., 2003; Malekzadeh et al., 2008; Shin et al., 2008; Noori et al., 2018; Lee \& Lee, 2019). In the design of the arched structure, it is most important to choose the suitable arch shape, so various linear shapes such as circular (Tufekci \& Ozdemir, 2006; Malekzadeh et al., 2008; Shin et al., 2008; Lü \& Lü, 2009; Lee et al., 2014), parabolic (Joo et al., 1985), elliptical (Nieh et al., 2003; Lee et al., 2016), catenary (Wilson \& Lee, 1995), elastica (Perkins, 1990), etc. have been studied. In addition, research topics include the variable cross-section (Tufekci \& Ozdemir, 2006; Shin et al., 2008; Noori et al., 2018), material properties (Malekzadeh et al., 2008; Lü \& Lü, 2009), and multi-span arches (Riedel \& Kang, 2009), etc. As mentioned above, the free vibration studies of arches are still being actively studied, from linear shapes to material properties of arches. As a study on AFG materials, studies are being conducted in the stability analysis (Chandran \& Rajendran, 2014; Ranganathan et al., 2016) and nonlinear behavior analysis (Horibe \& Mori, 2014). On the issue of free vibration of AFG arch, Lee and Lee $(2019 ; 2020)$ conducted a study but did not cover the horseshoe arch. It is considered that the free vibration characteristics of AFG horseshoe arch are one of the interesting subjects to be studied. In the open literature, the problem of free vibration of a horseshoe arch made of AFG material has not been reported. In the field of real engineering, AFG materials as well as conventional uniform materials are very important. In this regard, this paper focuses on the free vibration of AFG horseshoe arch. Differential equations governing in-plane free vibrations of AFG horseshoe circular arch are derived and numerically solved to compute natural frequencies with their mode shapes. Since the arched structure must maintain axial forces and bending moments, it is advisable to include tangential displacement due to axial forces in the analysis of the arched structure, this effect is included in this study. The effect of rotatory inertia couple on free vibration is included, but shear deformation is excluded in this study. Parametric studies affecting natural frequencies and mode shapes are conducted and discussed extensively discussed.

\section{Problem Formulation}

\subsection{Geometry of Arch}

Fig. 1(a) shows the geometry of the horseshoe circular arch with radius $r$ and the opening angle $\alpha(\pi \leq \alpha \leq 2 \pi)$. The arch shape is defined by the angular coordinates $(r, \theta)$ where the center of the circle is $\mathrm{O}$. Both ends $a(\theta=0)$ and $b(\theta=\alpha)$ of the arch are supported by the hinged or clamped end constraint. When the arch vibrates, it is natural that each of the radial displacement $w$, tangential displacement $v$ and angular rotation $\psi$ occurs in the cross-section at $(r, \theta)$. In this study, free vibrations assume a harmonic motion in which each dynamic coordinate is proportional to $\sin \left(\omega_{i} t\right)$. For example, 
dynamic radial displacement $w_{r, t}$ is expressed as $w_{r, t}=w \sin \left(\omega_{i} t\right)$, where $w$ is the radial amplitude (displacement), $\omega_{i}$ is the angular frequency, $i(=1,2,3, \cdots)$ is the mode number and $t$ is the time. As a result, dynamic axial force $N$, shear force $Q$ and bending moment $M$ occur in the cross-section of the arch due to displacements $(w, v)$.

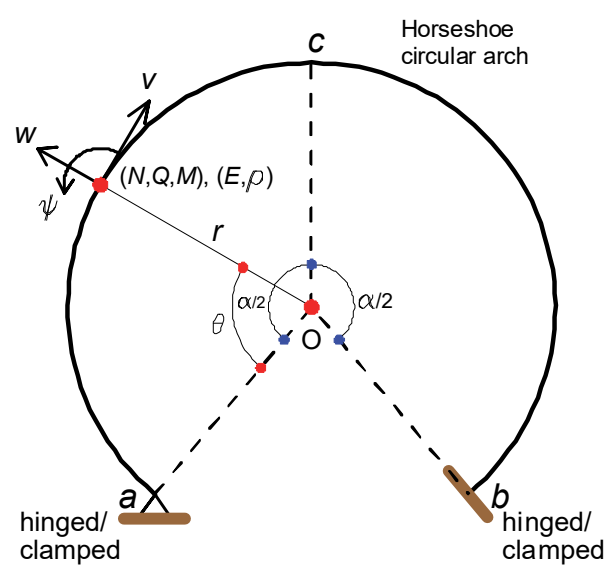

(a)

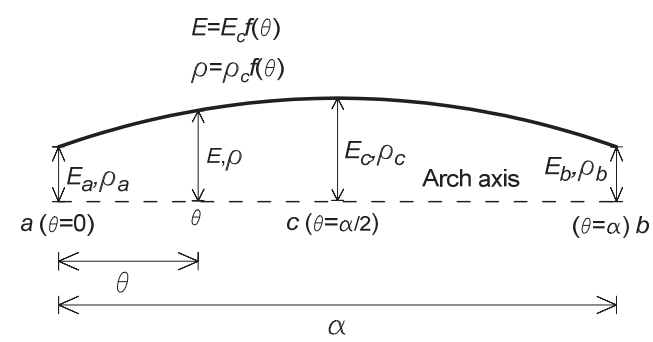

(b)

Fig. 1. Configuration of arch: (a) Geometry of AFG horseshoe circular arch, and (b) Variation function of mechanical properties

The arch is composed of AFG materials, as in Fig. 1 (b), where the modulus of elasticity $E$ and the mass density $\rho$ vary along the direction of the arch axis. The $(E, \rho)$ functions of AFG material are practically used in terms of linear (Chandran \& Rajendran, 2012), polynomial (Li, 2008), exponential (Noori et al., 2018) and periodic (Ranganathan et al., 2016) functions, etc. In this study, the functions $(E, \rho)$ are adopted as a quadratic polynomial (parabolic function) as shown in Fig. 1 (b) where $(E, \rho)$ at both ends $a$ and $b$ of the arch are $E_{a}\left(=E_{b}\right), \rho_{a}\left(=\rho_{b}\right)$, respectively, and $E_{c}, \rho_{c}$ at the central arc $(\theta=\alpha / 2)$. To determine the quadratic function of $(E, \rho)$, the following modular ratio (or mass density ratio) $m$ is defined as

$$
m=\frac{E_{a}}{E_{c}}\left(=\frac{\rho_{a}}{\rho_{c}}\right)
$$

Using Eq. (1), the variation function of $(E, \rho)$ adopted in this study can be expressed as a quadratic function in terms of a single variable $\theta$ :

$$
\begin{aligned}
& E=E_{c}\left[m_{1}\left(\frac{\theta^{2}}{\alpha^{2}}-\frac{\theta}{\alpha}\right)+m\right]=E_{c} f, \\
& \rho=\rho_{c} f
\end{aligned}
$$

where $f$ is a quadratic function for $\theta$ as follows. 
$f=m_{1}\left(\frac{\theta^{2}}{\alpha^{2}}-\frac{\theta}{\alpha}\right)+m ; m_{1}=4(m-1)$.

In the above Eq. (4), the equation $f$ is a convex distribution when $m>1$, a concave distribution when $m<1$, and a homogeneous material when $m=1$ (see Fig. 1 (b)).

\subsection{Governing Differential Equations}

Fig. 2 is a free body diagram acting on a small arch element in a free vibration state. The stress resultants $(N, Q, M)$ due to displacements $(w, v)$ act in the cross-section of this element and the radial inertia force $P_{r}$, the tangential inertia force $P_{t}$ and the rotatory inertia couple $T$ occur on this element having mass $\rho$ due to acceleration.

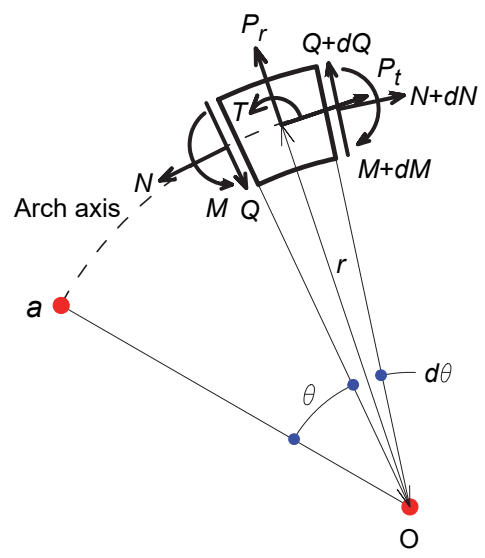

Fig. 2. Free body diagram of small arch element

In the free body diagram in Fig. 2, the equilibrium equations for $\sum F_{r}=0, \sum F_{t}=0, \sum M=0$ are as follows,

$$
\begin{aligned}
& N^{\prime}+Q+r P_{t}=0, \\
& Q^{\prime}-N+r P_{r}=0, \\
& \frac{M^{\prime}}{r}-Q-T=0,
\end{aligned}
$$

where $\left({ }^{\prime}\right)=d / d \theta$ and $\left({ }^{\prime \prime}\right)=d^{2} / d \theta^{2}$ of the differential operators. The equations that relate $(N, M)$ and $\psi$ to the displacements $(w, v)$ account for axial displacement due to $N$ as introduced in the Introduction. These equations, given in reference (Borg \& Gennaro, 1959), are

$$
\begin{aligned}
& N=\frac{E A}{r}\left(v^{\prime}+w\right)-\frac{M}{r}=\frac{E_{c} A}{r} f\left(v^{\prime}+w\right)-\frac{M}{r}, \\
& M=-\frac{E I}{r^{2}}\left(w^{\prime \prime}+w\right)=-\frac{E_{C} I}{r^{2}} f\left(w^{\prime \prime}+w\right), \\
& \psi=\frac{1}{r}\left(w^{\prime}-v\right),
\end{aligned}
$$

where $A$ is the cross-sectional area and $I$ is the second moment of plan area. The inertia loadings $\left(P_{r}, P_{t}, T\right)$ are given as (Weaver et al., 1990)

$$
\begin{aligned}
& P_{r}=\rho A \omega_{i}^{2} w=\rho_{c} A f \omega_{i}^{2} w \\
& P_{t}=\rho A \omega_{i}^{2} v=\rho_{c} A f \omega_{i}^{2} v, \\
& T=\rho I \omega_{i}^{2} \psi=\frac{\rho_{c} I}{r} f \omega_{i}^{2}\left(w^{\prime}-v\right) .
\end{aligned}
$$


In Eqs. (8) and (9), the first derivatives of $N^{\prime}, M^{\prime}$ are obtained as follows.

$$
\begin{aligned}
& N^{\prime}=\frac{E_{c} A}{r}\left[f\left(v^{\prime \prime}+w^{\prime}\right)+f^{\prime}\left(v^{\prime}+w\right)\right]-\frac{M^{\prime}}{r}, \\
& M^{\prime}=-\frac{E_{c} I}{r^{2}}\left[f\left(w^{\prime \prime \prime}+w^{\prime}\right)+f^{\prime}\left(w^{\prime \prime}+w\right)\right] .
\end{aligned}
$$

Substituting Eqs. (13) and (15) into Eq. (7) and arranging for the shear force $Q$ yields Eq. (16), and then the first derivative $Q^{\prime}$ is obtained from $Q$ as Eq. (17).

$$
\begin{aligned}
& Q=-\frac{E_{c} I}{r^{3}}\left[f\left(w^{\prime \prime \prime}+w^{\prime}\right)+f^{\prime}\left(w^{\prime \prime}+w\right)\right]-\frac{\rho_{c} I}{r} f \omega_{i}^{2}\left(w^{\prime}-v\right), \\
& Q^{\prime}=-\frac{E_{c} I}{r^{3}}\left[f\left(w^{\prime \prime \prime \prime}+w^{\prime \prime}\right)+2 f^{\prime}\left(w^{\prime \prime \prime}+w^{\prime}\right)+f^{\prime \prime}\left(w^{\prime \prime}+w\right)\right] \\
& -\frac{\rho_{c} I}{r} \omega_{i}^{2}\left[f\left(w^{\prime \prime}-v^{\prime}\right)+f^{\prime}\left(w^{\prime}-v\right)\right] .
\end{aligned}
$$

The following dimensionless parameters are defined to derive differential equations in dimensionless forms.

$$
\begin{aligned}
\delta & =\frac{w}{r}, \\
\lambda & =\frac{v}{r}, \\
s & =\frac{r}{\sqrt{I / A}} \\
C_{i} & =\omega_{i} r \sqrt{\rho_{c} / E_{c}},
\end{aligned}
$$

where $(\delta, \lambda)$ are the radial and tangential dimensionless displacements, $s$ is the slenderness ratio and $C_{i}$ is the frequency parameter. By substituting Eqs. (8), (11) and (17) into Eq. (6) and applying dimensionless parameters of Eq. (18)-(21), the differential equation of Eq. (22) can be obtained. Similarly, by substituting Eqs. (12), (14) and (16) into Eq. (5), the differential equation of Eq. (23) can be derived as follows,

$$
\begin{aligned}
& \delta^{\prime \prime \prime \prime}=-\frac{2 f^{\prime}}{f}\left(\delta^{\prime \prime \prime}+\delta^{\prime}\right)-\frac{f^{\prime \prime}}{f}\left(\delta^{\prime \prime}+\delta\right)-C_{i}^{2}\left\{\left(\delta^{\prime \prime}-\lambda^{\prime}\right)+\frac{f^{\prime}}{f}\left(\delta^{\prime}-\lambda\right)\right\} \\
& +s^{2}\left[\left(C_{i}^{2}-1\right) \delta-\lambda^{\prime}\right]-\left(2 \delta^{\prime \prime}+\delta\right), \\
& \lambda^{\prime \prime}=\frac{C_{i}^{2}}{s^{2}}\left(\delta^{\prime}-\lambda\right)-\delta^{\prime}-\frac{f^{\prime}}{f}\left(\delta+\lambda^{\prime}\right)-C_{i}^{2} \lambda,
\end{aligned}
$$

where derivatives of $f^{\prime}$ and $f^{\prime \prime}$ are obtained from Eq. (4), or

$$
f^{\prime}=m_{1}\left(\frac{2 \theta}{\alpha^{2}}-\frac{1}{\alpha}\right) ; f^{\prime \prime}=\frac{2 m_{1}}{\alpha^{2}} .
$$

In Eq. (22) above, the term in the bracket $\{\cdots\}$ is the term of the rotatory inertia couple $T$, and when the differential equation ignores $T$, the term in $\{\cdots\}$ is merely deleted. Eqs. (22) and (23) derived from above are differential equations governing free vibration of AFG horseshoe arch.

\subsection{Boundary Conditions}

Now consider the boundary conditions of the hinged and clamped end constraints at both ends of the arch $a$ and $b$. The displacements $(w, v)$ and the bending moment $M$ expressed by Eq. (9) at the hinged end $(\theta=0$ or $\theta=\alpha)$ are zero. By applying Eqs. (18) and (19) to the boundary conditions, the dimensionless boundary conditions of the hinged end can be obtained, or 
$\lambda=0$,

$\delta^{\prime \prime}=0$.

The displacements $(w, v)$ and the angular rotation $\psi$ expressed by Eq. $(10)$ at the clamped end $(\theta=$ 0 or $\theta=\alpha$ ) are zero. By applying Eqs. (18) and (19) to the boundary conditions, the dimensionless boundary conditions of the clamped end can be obtained, or

$$
\begin{aligned}
& \delta=0, \\
& \lambda=0, \\
& \delta^{\prime}=0
\end{aligned}
$$

As described above, the boundary conditions of the hinged and clamped end constraints for the differential equations of Eqs. (22) and (23) that govern the free vibration of the arch were derived.

\section{Solution Methods and Validation}

The input parameters of differential equations, Eqs. (22) and (23), are as follows: end constraint (hinged-hinged, hinged-clamped/clamped-hinged and clamped-clamped); opening angle $\alpha$; modular ratio $m$; and slenderness ratio $s$. The boundary conditions, Eqs. (25)-(30), were subjected to the differential equations according to the given end condition, and the frequency parameter $C_{i}$ with the mode shape $(\delta, \lambda)_{i}$ were calculated. In order to calculate $(\delta, \lambda)_{i}$, the differential equations were numerically integrated by the Runge-Kutta method (Burden et al., 2016), which is a direct integration method, and $C_{i}$ was calculated by the Determinant Search method enhanced by the Regula-Falsi method (Burden et al., 2016), which is a numerical solution method of the nonlinear equation. This kind of the numerical methods has been proven useful in the several literatures (Lee \& Lee, 2019), so detailed descriptions are omitted here. Before the numerical analysis, convergence analysis was performed for the accuracy of the numerical solutions. Since the accuracy of numerical solution is influenced by step size $\Delta \theta$ in the RungeKutta method (Burden et al., 2016), convergence analysis of $C_{i}$ was performed for the number of partitions $n_{d}$ of the arch axis as shown below:

$$
n_{d}=\frac{\alpha}{\Delta \theta}
$$

The input arch parameters used for convergence analysis are hinged-clamped, $\alpha=1.5 \pi, m=1.5$ and $s=100$. The convergence analysis for the lowest four $C_{i=1,2,3,4}$ were conducted and the results are shown in Fig. 3. As shown in this figure, the convergence of $C_{i}$ with increasing $n_{d}$ is very stable, and the reliability of the numerical solutions of this study can be confirmed. The solutions $C_{i}$ converged from $n_{d}=30$ to $n_{d}=200$ within the order of 3 significant figures (see $C_{3}$ ). Then, $n_{d}=50$ was used to calculate $C_{i}$ in this study.

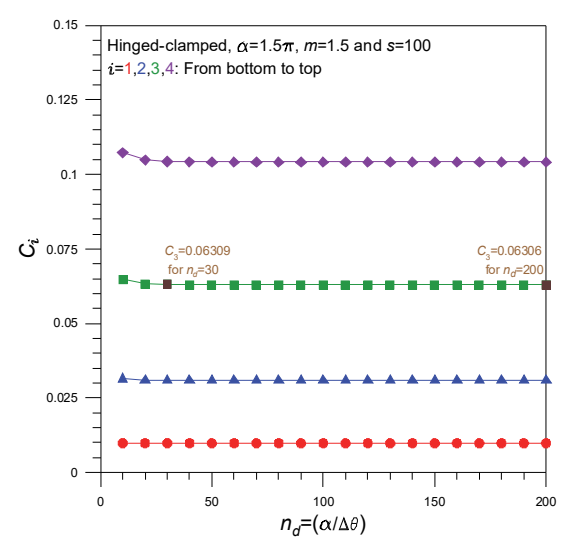

Fig. 3. Convergence analysis 
To verify the numerical analysis, Table 1 compares the angular frequency $\omega_{i}$ in $\mathrm{rad} / \mathrm{s}$ of this study and the finite element solution ADINA. The AFG material was synthesized from pure powder of $\mathrm{Al}$ and $\mathrm{Z}_{\mathrm{r}} \mathrm{O}_{2}$. The geometry of the arch and $(E, \rho)$ at both points $a$ and $c$ together with the dimensionless input parameters are listed in this table where $\omega_{i}$ of the two results is very close. The feasibility of this study could be verified with a maximum error of less than $2.0 \%$ and an average error of $1.55 \%$.

Table 1. Comparison* of angular frequency $\omega_{i}$ between ADINA and this study

\begin{tabular}{lllll}
\hline $\begin{array}{llll}\text { End } \\
\text { condition }\end{array}$ & $\begin{array}{l}\text { Mechanical properties of } E \text { and } \rho \\
\text { (non-dimensional parameters) }\end{array}$ & $i$ & & \multicolumn{2}{l}{ Angular frequency $\omega_{i}(\mathrm{rad} / \mathrm{s})$} \\
\cline { 5 - 5 } $\begin{array}{l}\text { Hinged- } \\
\text { hinged }\end{array}$ & $\mathrm{Al}: E_{a}=70 \mathrm{GPa}, \rho_{a}=2700 \mathrm{~kg} / \mathrm{m}^{3}$ & 1 & 85.96 & 87.04 \\
& $\mathrm{Z}_{\mathrm{r}} \mathrm{O}_{2}: E_{c}=140 \mathrm{GPa}, \rho_{c}=5400 \mathrm{~kg} / \mathrm{m}^{3}$ & 2 & 302.3 & 308.0 \\
& $(m=0.5, s=69.3, \alpha=1.2 \pi)$ & 3 & 649.7 & 661.3 \\
& & 4 & 1087. & 1106. \\
\hline $\begin{array}{l}\text { Hinged- } \\
\text { clamped }\end{array}$ & Homogeneous material & 1 & 84.61 & 85.53 \\
& $\mathrm{Al}: E_{a}=E_{c}=70 \mathrm{GPa}$, & 2 & 257.5 & 262.1 \\
& $\rho_{a}=\rho_{c}=2700 \mathrm{~kg} / \mathrm{m}^{3}$ & 3 & 526.4 & 535.6 \\
\hline Clamped- & $(m=1, s=69.3, \alpha=1.4 \pi)$ & 4 & 865.4 & 881.4 \\
clamped & $\mathrm{Z}_{\mathrm{r}} \mathrm{O}_{2}: E_{a}=140 \mathrm{GPa}, \rho_{a}=$ & 1 & 97.93 & 99.33 \\
& $5400 \mathrm{~kg} / \mathrm{m}^{3}$ & 2 & 239.7 & 243.9 \\
& $\mathrm{Al}: E_{c}=70 \mathrm{GPa}, \rho_{c}=2700 \mathrm{~kg} / \mathrm{m}^{3}$ & 3 & 457.8 & 463.9 \\
& $(m=2, s=69.3, \alpha=1.6 \pi)$ & 4 & 726.5 & 740.6 \\
\hline
\end{tabular}

*Arch geometry: $r=1 \mathrm{~m}, A=2.5 \times 10^{-3} \mathrm{~m}^{2}$ and $I=5.21 \times 10^{-7} \mathrm{~m}^{4}$.

\section{Numerical Examples and Discussion}

Table 2 shows the effect of the rotatory inertia couple $T$ on the frequency parameter $C_{i}$. The input arch parameters are $\alpha=1.5 \pi$ and $m=1.5$. Considering the effect of $T, C_{i}$ decreases compared to the case where $T$ is not considered. This is due to the dynamic characteristic that when considering $T$ in the dynamic analysis of a structure, the natural frequency decreases since the displacement increase under the same energy. The effect of $T$ on $C_{i}$ is greater in the higher order mode than in the lower order mode. For example, in the hinged-hinged arch, under the same $s=50$, the reduction rate of $i=1$ is $0.21 \%$ $(0.00977 / 0.00975=1.0021)$, but the larger reduction rate of $i=4$ is $2.04 \%$ $(0.19027 / 0.18646=1.0204)$. The effect of $T$ is greater for smaller slenderness ratio than for larger slenderness ratio. In the above hinged-hinged arch, under the same $i=4$, the reduction rate of $s=100$ is $0.64 \%(0.09402 / 0.09342=1.0064)$, which is smaller than the reduction rate $2.04 \%$ of $s=50$. Therefore, when a high frequency dynamic load is applied to an AFG horseshoe arch with small slenderness ratio, the influence of $T$ must be considered to accurately analyze the dynamic behavior.

In the subsequent discussion, the effect of $T$ was included, and the results of the hinged-clamped arch were not shown. Fig. 4 shows the natural frequency curve of the frequency parameter $C_{i}$ according to the change in the opening angle $\alpha$. The input arch parameters are $m=1.5$ and $s=100$. As $\alpha$ increases, $C_{i}$ decreases. As $\alpha$ increases, the span length of the arch decreases, while the height increases and structural stiffness of the arch decreases, resulting in a decrease in $C_{i}$. In the hinged-hinged arch, when the arch becomes a complete circle of $\alpha=2 \pi$ marked with $\bigcirc, C_{i}$ vanishes, i.e. $C_{i}=0$ and the arch becomes unstable. The hinged-hinged arch with $\alpha=2 \pi$ means that the whole structure becomes 'unstructured' because it cannot resist the lateral load. This is consistent with the results of the free vibrations of elastica arch (Perkins, 1990). The clamped-clamped arch with $\alpha=2 \pi$ can maintain a stable state because it can resist the lateral load at the clamped end. 
Table 2. Effect of rotatory inertia couple $T$ on frequency parameter $C_{i}$

\begin{tabular}{|c|c|c|c|c|c|c|}
\hline \multirow{2}{*}{$\begin{array}{l}\text { End } \\
\text { condition }\end{array}$} & \multirow[b]{2}{*}{$S$} & \multirow[b]{2}{*}{$T$ index $^{*}$} & \multicolumn{4}{|c|}{ Frequency parameter $C_{i}$} \\
\hline & & & $i=1$ & $i=2$ & $i=3$ & $i=4$ \\
\hline \multirow{4}{*}{$\begin{array}{l}\text { Hinged- } \\
\text { hinged }\end{array}$} & \multirow[t]{2}{*}{50} & 0 & 0.00977 & 0.04898 & 0.11007 & 0.19027 \\
\hline & & 1 & 0.00975 & 0.04869 & 0.10831 & 0.18646 \\
\hline & \multirow[t]{2}{*}{100} & 0 & 0.00488 & 0.02440 & 0.05447 & 0.09402 \\
\hline & & 1 & 0.00488 & 0.02436 & 0.05421 & 0.09342 \\
\hline \multirow{4}{*}{$\begin{array}{l}\text { Hinged- } \\
\text { clamped }\end{array}$} & \multirow[t]{2}{*}{50} & 0 & 0.01973 & 0.06227 & 0.12798 & 0.21229 \\
\hline & & 1 & 0.01969 & 0.06188 & 0.12592 & 0.20782 \\
\hline & \multirow[t]{2}{*}{100} & 0 & 0.00986 & 0.03103 & 0.06337 & 0.19496 \\
\hline & & 1 & 0.00985 & 0.03097 & 0.06307 & 0.10420 \\
\hline \multirow{4}{*}{$\begin{array}{l}\text { Clamped- } \\
\text { clamped }\end{array}$} & \multirow[t]{2}{*}{50} & 0 & 0.03066 & 0.07607 & 0.14692 & 0.23506 \\
\hline & & 1 & 0.03059 & 0.07558 & 0.14455 & 0.22996 \\
\hline & \multirow[t]{2}{*}{100} & 0 & 0.01532 & 0.0371 & 0.07278 & 0.11640 \\
\hline & & 1 & 0.01530 & 0.03784 & 0.07242 & 0.11542 \\
\hline
\end{tabular}

${ }^{*} T$ index=0: without rotatory inertia couple; index=1: with.
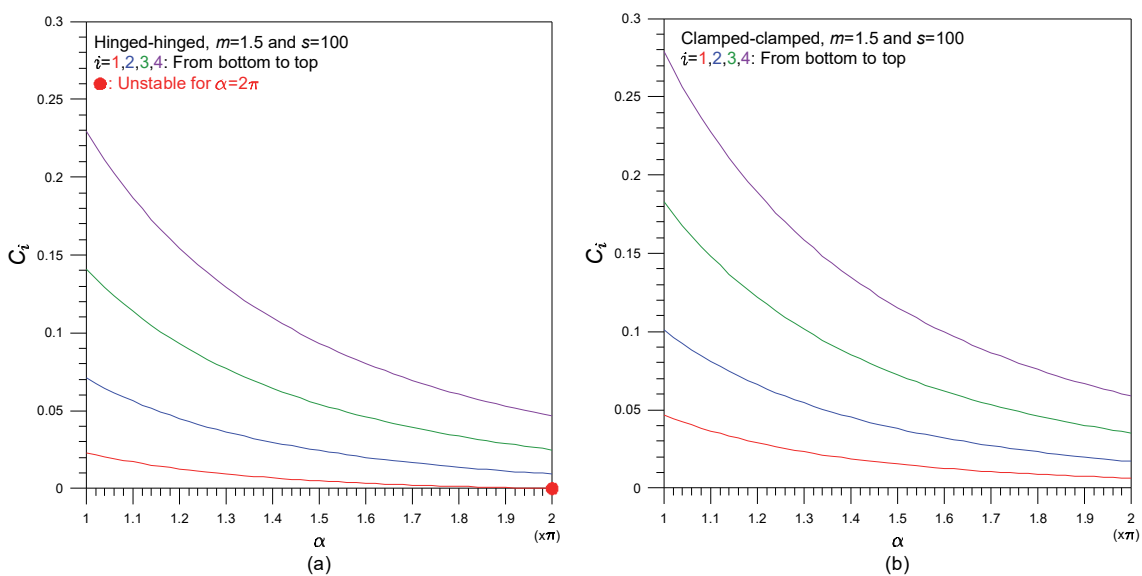

Fig. 4. $C_{i}$ versus $\alpha$ curves: (a) Hinged-hinged ends, and (b) Clamped-clamped ends
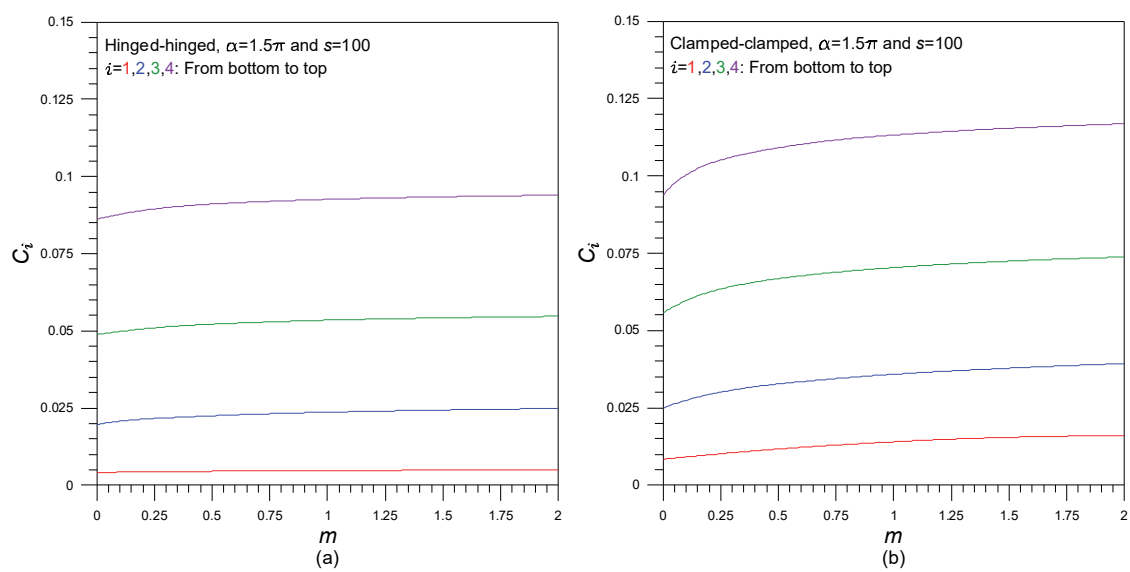

Fig. 5. $C_{i}$ versus $m$ curves: (a) Hinged-hinged ends, and (b) Clamped-clamped ends

Fig. 5 shows the natural frequency curve of the frequency parameter $C_{i}$ according to the change in the modular ratio $m$. The input arch parameters are $\alpha=1.5 \pi$ and $s=100$. As $m$ increases, $C_{i}$ increases. The rate of increase for $C_{i}$ is very gentle, so it is judged that the influence of $m$ is relatively small. When $m$ is large, AFG arch are synthesized from smaller $\left(E_{c}, \rho_{c}\right)$ and larger $\left(E_{a}, \rho_{a}\right)$. Therefore, by placing a more robust composite material at both ends $a$ and $b$ of the horseshoe arch, a structurally more robust 
arch can be realized. Fig. 6 shows the natural frequency curve of the frequency parameter $C_{i}$ according to the change in the slenderness ratio $s$. The input arch parameters are $\alpha=1.5 \pi$ and $m=1.5$. As $s$ increases, $C_{i}$ decreases. As $s$ increases, the structural stiffness of the arch decreases, so $C_{i}$ decreases. In the small region of $S$, the spacing between natural frequency curves is wide, but as $S$ increases, the spacing gradually narrows. Therefore, the effect of $s$ on $C_{i}$ has a greater effect on smaller $s$. On the other hand, it can be seen that $C_{i}$ values are concentrated in a narrow frequency band in a large region of $s$. In such a narrow band range, the arch under dynamic load is likely to cause resonance. From this point of view, from the design stage, it is important to determine the suitable $s$ value of the arch by using the natural frequency curve such as Fig. 6 to have the natural frequency that can avoid resonance.
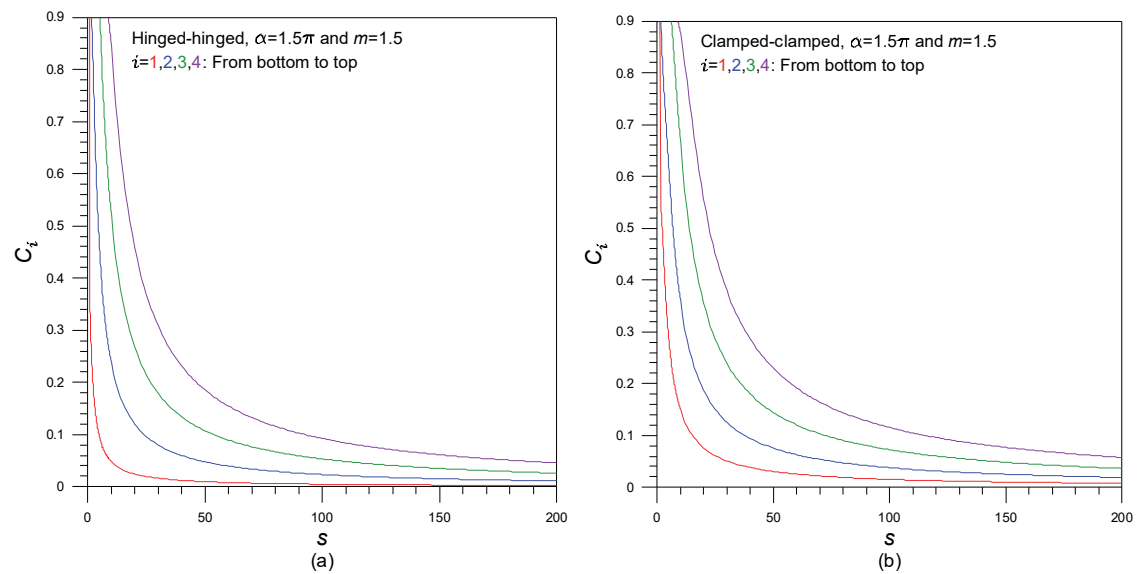

Fig. 6. $C_{i}$ versus $s$ curves: (a) Hinged-hinged ends, and (b) Clamped-clamped ends

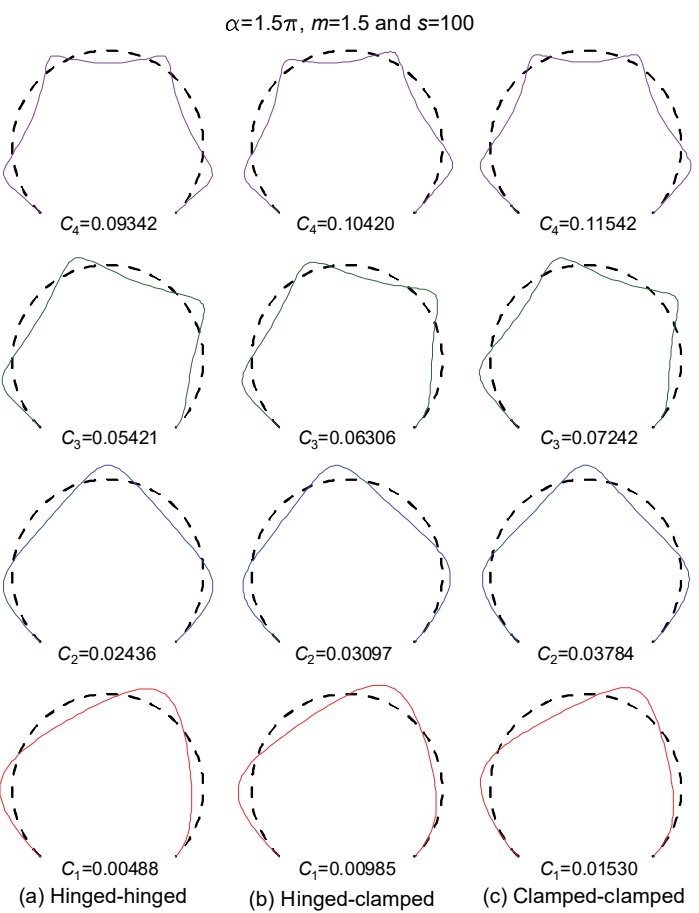

Fig. 7. Example of mode shapes: (a) Hinged-hinged, (b) Hinged-clamped, and (c) Clamped-clamped

Fig. 7 shows example of mode shapes of the hinged-hinged, hinged-clamped and clamped-clamped arch. The input arch parameters are $\alpha=1.5 \pi, m=1.5$ and $s=100$. In the numerical analysis of differential equations, the radial and tangential displacements $(\delta, \lambda)$ are calculated separately. Since these two displacement vectors are perpendicular to each other as shown in Fig. 1, the two displacements are represented as one synthesized mode shape. In $C_{i}$ values shown in this figure, the end constraint has a 
great influence on $C_{i}$ computations. There is no significant difference between 3 mode shapes except for the presence or absence of angular rotation at both ends $a$ and $b$ of the arch (see boundary conditions, Eqs. (27) to (30)). That is, there are no significant differences of the nodal points and the maximum amplitude positions between 3 mode shapes. The position of the maximum displacement shown in Fig. 7 is important for structural safety, and when exposed to dynamic loads over a long period of time, there is a high possibility of fatigue fracture due to resonance, so a periodic soundness check is required at the maximum amplitude positions of the horseshoe arch.

\section{Conclusions}

This study deals with free vibration analyses of the axially functionally graded (AFG) horseshoe circular arch. Differential equations governing free vibrations of such arch were derived by applying the equilibrium equations of the arch element acting the stress resultants and inertia forces. These differential equations were numerically solved using the direct integration method and the determinant search method, and the natural frequencies with their mode shapes were calculated. In this study, the conclusions obtained through the parametric study on the free vibration of AFG horseshoe arch are as follows.

1. The natural frequencies of this study and the finite element ADINA agree well.

2. The rotatory inertia couple is a factor that decreases the natural frequency and has a greater influence in the lower mode and larger slenderness ratio.

3. As the opening angle increases, the natural frequency decreases.

4. As the modular ratio increases, the natural frequency increases.

5. As the slenderness ratio increases, the natural frequency decreases.

It is expected that the results obtained in this study can be used for the dynamic analysis and design of AFG horseshoe arch. As a future research work, studies on the free vibration analysis of AFG horseshoe arch with the variable curvature and the non-uniform cross-section should be necessary.

\section{Acknowledgements}

This study was supported by the Wonkwang University Research Fund in 2021, which is very much appreciated.

\section{References}

Borg, S.F. \& Gennaro, J.J. (1959). Advanced structural analysis. Van Nostrand Reinhold Company, New York, NY, USA.

Burden, R.L. \& Faires, D.J. \& Burden, A.M. (2016). Numerical analysis. Cengage Learning, Boston, MA, USA.

Chandran, G. \& Rajendran, M.G. (2014). Study on buckling of column made of functionally graded material. International Journal of Mechanical and Production Engineering, 2(2), 52-54.

Horibe, T. \& Mori, K. (2018). Large deflections of tapered cantilever beams made of axially functionally graded materials. Mechanical Engineering Journal, Japan Society of Mechanical Engineers, 5, 1-10.

Joo, S.M., Park, K.K., Lee, B.K. \& Hwang, H.J. (1985). Free vibration analysis of fixed ended parabolic arches. Journal of Korean Society of Civil Engineers, 5(3), 31-38 (in Korean).

Lee, B.K., Oh, S.J. \& Lee, T.E. (2014). In-plane free vibrations of horseshoe circular arch. Journal of the Korean Society of Civil Engineers, 34(4), 1043-1052 (in Korean).

Lee, B.K., Park, K.K., Oh, S.J. \& Lee, T.E. (2016). Planar free vibrations of horseshoe elliptic arch. KSCE Journal of Civil Engineering, 20 (4), 1411-1418.

Lee, J.K. \& Lee, B.K. (2019). Free vibration and buckling of tapered columns made of axially functionally graded materials. Applied Mathematical Modelling, 75, 73-87. 
Lee, J.K. \& Lee, B.K. (2020). Free vibration of AFG circular arch with symmetric and anti-symmetric boundary conditions at mid-arc. Symmetry-Basel, 12, 417 (14 pages).

Li, X. (2008). A unified approach for analyzing static and dynamic behaviors of functionally graded Timoshenko and Bernoulli-Euler beam. Journal of Sound and Vibration, 318, 1211-1229.

Lü, Q. \& Lü, C.F. (2009). Exact two-dimensional solutions for in-plane natural frequencies of laminated circular arches. Journal of Sound and Vibrations, 318(4-5), 982-920.

Malekzadeh, P., Setoodeh, A.R. \& Barmshouri, E. (2008). A hybrid layerwise and differential quadrature method for in-plane free vibration of laminated thick circular arches. Journal of Sound and Vibration, $315(1-2), 212-225$.

Nieh, K.Y., Huang, C.S. \& Tseng, Y.P. (2003). An analytical solution for in-plane free vibration and stability of loaded elliptic arches. Computers \& Structures, 81(13), 1311-1327.

Noori, A.R., Aslan, T.A. \& Temel, B. (2018). An efficient approach for in-plane free and forced vibrations of axially functionally graded parabolic arches with nonuniform cross section. Composite Structures, 200, 701-710.

Perkins, N.C. (1990). Planar vibration of an elastica arch: Theory and Practice. Journal of Vibration and Acoustics, 112, 374-379.

Ranganathan, S., Abed, F. \& Aldadah, M.G. (2016). Buckling of slender columns with functionally graded micro-structures. Mechanics of Advanced Materials and Structures, 23, 1360-1367.

Rao, S.S. (2007). Vibration of continuous system. John Wiley \& Sons, Inc., Hoboken, NJ, USA.

Riedel, C.H. \& Kang, B.S. (2006). Free vibration of elastically coupled dual-span curved beams. Journal of Sound and Vibration, 290(3-5), 820-838.

Shin, Y.J., Kwon, K.M. \& Yun, J.H. (2008). Vibration analysis of a circular arch with variable crosssection using differential transformation and generalized differential quadrature. Journal of Sound and Vibration, 309(1-2), 9-19.

Tufekci, E. \& Ozdemir, O. (2006). Exact solution of free in-plane vibration of a stepped circular arch. Journal of Sound and Vibration, 295(3-5), 725-738.

Weaver, W., Timoshenko, S.P. \& Young, D.H. (1990). Vibration problems in engineering. John Wiley \& Sons, Inc., Hoboken, NJ, USA.

Wilson, J.F. \& Lee, B.K. (1995). In-plane free vibrations of catenary arches with unsymmetric axes. Structural Engineering and Mechanics, 3(3), 511-525. 
(C) 2021 by the authors; licensee Growing Science, Canada. This is an open access article distributed under the terms and conditions of the Creative Commons Attribution (CC-BY) license (http://creativecommons.org/licenses/by/4.0/). 